\title{
The Mayo Clinic Department of Orthopedic Surgery: an international foundation
}

\author{
Matthew P. Abdel • Mark E. Morrey • \\ Sébastien Parratte $\cdot$ Nicolaas Budhiparama . \\ Bernard F. Morrey
}

Received: 8 January 2015 / Accepted: 14 January 2015/Published online: 22 January 2015

(C) Springer-Verlag France 2015

In our series of editorials planned for 2015, we give the opportunity to our friends from the Mayo Clinic (Rochester, MN, USA) to present their state-of-the-art institution and Department of Orthopedic Surgery [1].

The Mayo Clinic Department of Orthopedic Surgery in Rochester, Minnesota, has been an international foundation since its inception. Drs. William James and Charles Horace Mayo were always interested in innovative ideas and surgical techniques from across the world. With their father's origin from Eccles, near Manchester, England, it made sense that they visited Sir Robert Jones in 1906 [5]. The Mayo brothers documented their visit in an article entitled "Present-day Surgery in England and Scotland: From notes made on a recent short visit" published in the Journal of the Minnesota Medical Association [3]. After

\footnotetext{
M. P. Abdel ( $₫)$ · M. E. Morrey · B. F. Morrey

Department of Orthopedic Surgery, Mayo Clinic,

200 First Street S.W, Rochester, MN 55905, USA

e-mail: abdel.matthew@mayo.edu

M. E. Morrey

e-mail: morrey.mark@mayo.edu

B. F. Morrey

e-mail: morrey.bernard@mayo.edu

S. Parratte

Department of Orthopedics and Traumatology, St. Marguerite Hospital, 270 Boulevard Sainte Marguerite, BP 29,

13274 Marseille, France

e-mail: sebastien@parratte.fr

N. Budhiparama

Nicolaas Institute of Constructive Orthopaedics Research and Education Foundation for Arthroplasty and Sports Medicine, Medistra Hospital, Jl. Jend. Gatot Subroto Kav. 59,

Jakarta 12950, Indonesia

e-mail: ncbjr@yahoo.com
}

visiting Sir Robert Jones in Liverpool, Dr. William J. Mayo described the number of rooms and the manner in which Sir Robert Jones saw his patients, noting that much of the clerical work was completed by his associates [5]. Mayo also noted Jones' ability to use splints, plaster, and alternative means of immobilization to treat patients postoperatively. Several years later, Dr. William J. Mayo established an independent Department of Orthopedic Surgery at the Mayo Clinic in Rochester, Minnesota. Moreover, the Mayo brothers encouraged Dr. M. S. Henderson to visit Liverpool to learn from Sir Robert Jones. While in Liverpool, he stayed at Sir Robert's home at 11 Nelson Street [5]. When Dr. Henderson returned to the Mayo Clinic, he adopted the process of seeing patients and managing their musculoskeletal affliction, often without compensation, similar to the practice he experienced in Liverpool.

The Department of Orthopedic Surgery at the Mayo Clinic was formally created in 1910, and its first official chair was Dr. Henderson [4]. Dr. Henderson worked closely with Dr. Charles H. Mayo and was responsible for the majority of the orthopedic cases. Under the original guidance of the Mayo brothers and Dr. Henderson, the present-day staff has grown to 56 physician/scientist faculty appointments, and 72 residents and fellows [4]. From the Mayo Clinic Department of Orthopedic Surgery, there have been five American Academy of Orthopaedic Surgeons presidents, including Dr. M. S. Henderson (1935), Dr. W. Bickle (1964), Dr. E. D. Henderson (1976), Dr. B. F. Morrey (1994), and Dr. D. J. Berry (2011) [4]. Likewise, there have been five American Orthopaedic Association (AOA) presidents, including Dr. M. S. Henderson (1934), Dr. R. K. Ghormley, Dr. M. B. Coventry (1970), Dr. P. Lipscomb (1975), and Dr. B. F. Morrey (2002) [4]. 
The rich history of the Mayo Clinic and the Department of Orthopedic Surgery is of course much deeper and longer-lasting. For instance, the first partner to join the Mayo brothers was Dr. Augustus W. Stinchfield in 1892 [4]. He was the father-in-law of Dr. Henry W. Meyerding. Another Minnesota resident, Dr. Frank E. Stinchfield, was a former chair and director of the New York Orthopaedic Hospital from 1956 to 1976 at Columbia University (New York, New York). More recently, the Mayo Clinic Department of Orthopedic Surgery was honored to have President George H.W. Bush and Mrs. Barbara Bush join us for our centennial celebration in 2010.

In 2015 and moving forward, the Mayo Clinic Department of Orthopedic Surgery remains dedicated to providing world-class patient care, completing state-of-the-art research, and singularly educating the best residents and fellows in the world. Concurrently, we continue the dynamic interaction and symbiotic growth with friends and colleagues locally, nationally, and internationally. Most importantly, our moral and values have remained unchanged. Our focus is best characterized in the cryptic admonition of Dr. William J. Mayo in 1910, "The best interest of the patient is the only interest to be considered, and in order that the sick may have the benefit of advancing knowledge, union of forces is necessary" [2]. This remains the beacon of the Mayo Clinic and of our Department of Orthopedic Surgery.

Conflict of interest Dr. S. Parratte reports personal fees from Zimmer, personal fees from Adler Ortho, personal fees from Graftys, and personal fees from Arthrex outside the submitted work. Dr. Budhiparama reports grants and personal fees from DePuy Johnson \& Johnson, grants from Zimmer, grants from Bayer, grants and personal fees from Pfizer, personal fees from Sanofi Aventis, grants from Biomet, and personal fees from Smith \& Nephew outside the submitted work. Dr. M. Abdel, Dr. M. Morrey, and Dr. B. Morrey: None.

\section{References}

1. Kehr P (2014) A new direction for EJOST! Eur J Orthop Surg Traumatol 24(8):1329

2. Mayo WJ (1910) The necessity of cooperation in the practice of medicine. In: Collected papers by the Staff of St. Mary's Hospital, Mayo Clinic, pp 557-566

3. Mayo WJ (1907) Present-day surgery in England and Scotland: from notes made on a recent short visit. J Minn Med Assn: 499-503

4. Morrey BF (ed) (2010) 100 Years of orthopedic surgery at the Mayo Clinic, 1910-2010. Rochester, MN

5. Morrey BF (2005) The influence of Sir Robert Jones on the founding and development of orthopaedic surgery at the Mayo Clinic. J Bone Joint Surg Br 87:106-107 